\title{
IMPLEMENTASI KEBIJAKAN PENYELENGGARAAN PENDIDIKAN NASIONAL PADA PENYELENGGARAAN PENDIDIKAN TENAGA KESEHATAN PROGRAM D-III KEPERAWATAN DI PROPINSI DKI JAKARTA
}

\author{
ELSYE MARIA ROSA*
}

\begin{abstract}
The objective of this research is to analyze the implementation of national education policy in the nursing education D-III program in Jakarta Province. The evaluation was based on the implementation of the National Education Systems No. 20 year 2003. The research was conducted at the Akademi keperawatan province in Jakarta. It was using policy analysis method. The sample of this research were 7 person of Akademi Keperawatan, Pusdiknakes and Kopertis 3 that was selected randomly. NVIVO version 8 was used to analyze the data collected.

The research findings are: (1) most of the nursing educations were Diploma III vocational educations; (2) the ownership status of nursing academies was in the hand of private; (3) the management of diploma III nursing education owned by public was mostly executed by the Department of Health through the Center of Health National Education and Agency for Health of the Jakarta Province; (4) three duty university was not yet implemented completely as a mandatory reference for the institutions and lecturers.

Based on these findings, it could be concluded that --- the implementation of National Education Systems No. 20 year 2003 in performing nursing education diploma III was not carried out well. This was happened because of the involving parties were not able to cooperate effectively and efficiently. Transitional management by the Department of Health, in this case the Center of Health National Education and Agency for Health of the Jakarta Province was not implemented thoroughly. Thereby, the implementation of the National Education Law No. 20 year 2003 could be in jeopardy simply because of its inappropriate execution.
\end{abstract}

Keywords : National Education Systems No. 20 year 2003, Nursing education D-III Program

\section{PENDAHULUAN}

Mutu pengelolaan proses pembelajaran dinilai dari efisiensi, akuntabilitas dan memiliki program kerja yang terencana dan terfasilitasi dengan baik; satuan biaya kompetitif, berbagai fasilitas kemudahan studi; otonomi penyelenggaraan, fleksibel, akuntabilitas, dalam jaringan kerjasama penyelenggaraan pendidikan secara nasional maupun internasional. Dalam UU RI no.20 tahun 2003 dijelaskan bahwa penyelenggarakan pendidikan tinggi di perguruan tinggi, dapat berbentuk pendidikan akademik, pendidikan profesi, dan/atau pendidikan vokasi. Perguruan tinggi dapat berbentuk akademi, politeknik, sekolah tinggi, institut, atau universitas.

Salah satu bentuk penyelenggaraan pendidikan keprofesian diantaranya adalah pendidikan program D-III Keperawatan. Pendidikan D-III Keperawatan berbentuk pendidikan vokasi yaitu pendidikan tinggi yang mempersiapkan peserta didiknya untuk memiliki pekerjaan dengan keahlian terapan tertentu.

Keperawatan sebagai profesi yang masih dalam proses menuju "perwujudan diri". Profesi keperawatan dihadapkan pada berbagai tantangan, diantaranya adalah pembenahan internal yang meliputi empat dimensi yaitu; 1) Pendidikan keperawatan,

\footnotetext{
* Dosen di prodi Manajemen Rumah Sakit Universitas Muhammadiyah Yogyakarta
} 
2) pelayanan keperawatan, 3) asuhan keperawatan, dan 4) praktik keperawatan. Belum lagi tantangan eksternal berupa tuntutan akan adanya registrasi, lisensi, sertifikasi, kompetensi dan perubahan pola penyakit, peningkatan kesadaran masyarakat akan hak dan kewajiban, perubahan system pendidikan nasional, serta perubahan-perubahan pada supra system dan pranata lain yang terkait.

Sejak dicanangkannya UU RI no.20 tahun 2003, implementasi pada institusi pendidikan D-III Keperawatan mengalami dilema. Mengingat penerapannya belum sepenuhnya dilaksanakan oleh seluruh penyelenggara program D-III Keperawatan. Institusi melaksanakan peralihan pembinaan pada Depdiknas tetapi managemen pendidikan yang seyogyanya dilakukan sebagaimana diatur dalam Undang-Undang, peraturan pemerintah terkait pelaksanaan pendidikan di bawah pembinaan Diknas cenderung diabaikan.

Bagi institusi yang menginginkan penyehatan manajemen pendidikan untuk mencapai mutu pendidikan yang diinginkan, berusaha untuk menjalankan kaidahkaidah pendidikan yang ditentukan Undang-Undang, akan beralih pembinaan pada Depdiknas dan menjalankan segala aturannya. Tetapi fakta yang terjadi sekarang adalah adanya 2 macam penyelenggaraan program D-III Keperawatan yaitu Akademi Keperawatan yang mengikuti pembinaan dengan Depdiknas dan Akademi Keperawatan mengikuti kebijakan Depkes. Sehingga muncul istilah Anak Depdiknas (di bawah binaan Depdiknas) dan Anak Depkes (di bawah binaan Depkes).

Kesimpang siuran tersebut diperparah oleh adanya institusi yang mengikuti peraturan atau kebijakan dari Depdiknas hanya untuk memberikan keuntungan bisnis dan mengabaikan peraturan dengan dalih demokrasi, desentralisasi, otonomi, keadilan dan menjunjung tinggi hak asasi manusia dalam mencerdaskan Bangsa.

Dengan keluarnya Undang-undang RI no.20 tahun 2003 tentang Sistem Pendidikan Nasional, maka diperlukan kesepakatan baru tentang sistem pendidikan tinggi keperawatan agar output dari sistem ini dapat menjadi input bagi sistem kesehatan nasional dan memberi kontribusi bermakna pada pembangunan kesehatan. Diharapkan terjadi sinkronisasi antara peraturan Perundang-Undangan yang berlaku dalam hal ini Undang-undang RI no.20 tahun 2003 dengan penyelenggaraan pendidikan tenaga kesehatan terutama pada program D-III Keperawatan.

Dengan keluarnya Undang-undang RI no.20 tahun 2003 tentang Sistem Pendidikan Nasional, maka diperlukan kesepakatan baru tentang sistem pendidikan tinggi keperawatan agar output dari sistem ini dapat menjadi input bagi sistem kesehatan nasional dan memberi kontribusi bermakna pada pembangunan kesehatan.

\section{Kebijakan Publik}

Salah satu definisi mengenai kebijakan publik diberikan oleh Robert Eyestone, yang menyatakan "secara luas" bahwa kebijakan publik dapat didefinisikan sebagai "hubungan suatu unit pemerintah dengan lingkungannya". Batasan lain dikemukakan oleh Thomas R.Dye yang mengatakan bahwa "Kebijakan publik adalah apapun yang dipilih oleh pemerintah untuk dilakukan dan tidak dilakukan". Kebijakan dapat didefinisi menjadi 2 macam yaitu : Katagori pertama, definisi yang lebih menekankan pada maksud dan tujuan utama sebagai kunci kriteria kebijakan dan katagori kedua, lebih menekankan pada dampak dari tindakan pemerintah berkaitan dengan pemerintah tersebut.

Definisi kebijakan yang lebih menekankan pada maksud dan tujuan utama dapat diidentifikasi sebagai berikut: 
a. "A purposive course of action followed by an actor or set of actors in dealing with a problem or matter of concern......Publik policies are those policies developed by govermental bodies an official".

b. "Publik policy is whatever government choose to do or not to do".

Definisi Kebijakan publik tersebut mengandung makna bahwa (1) kebijakan publik tersebut dibuat oleh badan pemerintah, bukan organisasi swasta; (2) kebijakan publik menyangkut pilihan yang harus atau tidak dilakukan oleh badan pemerintah. Senada dengan pendapat tersebut memaknai kebijakan publik adalah kebijakan yang dibuat oleh pemerintah

Dengan demikian yang membedakan antara kebijakan pemerintah dan bukan bukan kebijakan pemerintah ialah : (1) bahwa kebijakan perintah dibuat oleh suatu badan pemerintah, baik pejabat maupun instansi pemerintah; (2) bahwa kebijakan dibuat dalam rangka hubungan pemerintah dengan masyarakat (sebagian besar warga masyarakat/publik); (3) kebijakan merupakan pilihan pemerintah baik melakukan maupun tidak melakukan sesuatu yang menyangkut masyarakat banyak.

Karakteristik utama model Eastonian adalah model ini melihat proses kebijakan dari segi input yang diterima, dalam bentuk aliran dari lingkungan, dimediasi melalui saluran input (partai, media,kelompok kepentingan); permintaan di dalam system politik (withinput) dan konversinya menjadi output dan hasil kebijakan

Sementara pengertian Kebijakan Publik yang lebih menekankan pada dampak, diidentifikasi sebagai berikut :

1. What government actually do and why (Richard Simeon)

2. Action taken by government (Ira Sharkansky)

3. A policy may usefully be considered as a course of action or inaction rather than specific decision or action, and such a course has to be perceived and identified by the analysis in question.

Berdasarkan pengertian tersebut diatas, sistem kebijakan terdapat tiga elemen yaitu a) Kebijakan publik, b) pelaku kebijakan dan c) lingkungan kebijakan. Dunn juga mengemukakan bahwa dalam system kebijakan terdapat tiga elemen yaitu, a) stakeholders kebijakan (policy actor), b) kebijakan publik (policy content) dan c) lingkungan kebijakan (policy environment).

\section{A. Tahap-tahap Kebijakan Publik}

Proses pembuatan kebijakan publik merupakan proses yang kompleks karena melibatkan banyak proses dan variabel harus dikaji. Tahap-tahap kebijakan publik adalah sebagai berikut:

1. Tahap Penyusunan Agenda

2. Tahap formulasi kebijakan

3. Tahap adopsi kebijakan

4. Tahap implementasi kebijakan

5. Tahap penilaian kebijakan

\section{B. Implementasi Kebijakan}

Implementasi adalah melakukan suatu keputusan kebijakan dasar, biasanya dimasukkan dalam undang-undang, tetapi juga merupakan bentuk perintah yang penting atau keputusan pengadilan. Idealnya, keputusan yang mengidentifikasi 
masalah yang harus diatasi, menetapkan sasaran dalam berbagai cara, bentuk proses implementasi. Implementasi pada prinsipnya adalah cara agar sebuah kebijakan dapat mencapai tujuannya. Tidak lebih dan tidak kurang. Untuk mengimplementasikan kebijakan publik ada dua pilihan langkah yaitu langsung mengimplementasikan dalam bentuk program aau melalui formulasi kebijakan derivate atau turunan dari kebijakan publik tersebut.

\section{Analisis Implementasi Kebijakan}

Tahap kebijakan yang mengikuti rekomendasi kebijakan, setelah diputuskan/dibuatnya kebijakan berdasar rekomendasi tersebut, adalah implementasi kebijakan. Tahap implementasi ini sepenuhnya dikelola oleh pengambil kebijakan (policy maker). Tahap analisis implementasi kebijakan merupakan suatu analisis yang bersifat evaluatif, dengan konsekuensi lebih melakukan retrospeksi ketimbang prospektif. Ia berusaha mengenali sejauh mana efek yang semula direncanakan untuk dicapai oleh kebijakan telah terealisir dan dampak apa yang ditimbulkan olehnya (baik dampak yang terduga maupun tak terduga).

Salah satu model implementasi kebijakan adalah Model dari Richard Matland yang disebut Matriks Ambiguitas -Konflik.

\section{Analisis Proses Evaluasi Kebijakan Publik}

\section{Pengertian Evaluasi Publik}

Jones (1996) mengartikan evaluasi public sebagai" ....an activity designed to judge the merits of government policies which varies significantly in the specification of object, the techniques of measurement, and the method of analysis". Menurut Weiss (1972) menyatakan "the purpose of evaluation research is to measure the effect of a program again the goals it set out to accomplish as of contributing to subsequent decision making about the program and improving future programming".

\section{Tipe Evaluasi Kebijakan Publik}

Langbein (1980:5) membedakan tipe riset evaluasi menjadi 2 macam tipe yaitu research process dan research outcomes. Metode riset evaluasi juga dibedakan menjadi dua macam yaitu metode deskriptif dan kausal. Metode deskriptif lebih mengarah pada tipe penelitian evaluasi proses (process of policy implementation), sementara metode kausal lebih mengarah pada tipe penelitian evaluasi dampak (outcomes of public policy implementation). Rossi (1979: 3250) juga membedakan riset evaluasi lebih komprehensif. 3.

\section{Tahapan Proses Evaluasi Kebijakan Publik}

Penelitian evaluasi kebijakan publik terdapat beberapa tahapan yang perlu diikuti. Menurut Weiss (1972: 24-25) mengemukakan tahapan yang harus dilakukan oleh peneliti evaluasi kebijakan public sebagai berikut:

a. Find out the program's goals

$b$. Translate the goals into measurable indicators of goal achievement

c. Collect data the indicator for those who participated in the program (and for equivalent control group who did not)

d. Compare the data on participants and controls with the goal criteria.

Sementara Jones (1996) menjelaskan evaluasi kebijakan lebih operasional yaitu sebagai aktivitas yang dirancang untuk menilai hasil-hasil kebijkan pemerintah 
yang mempunyai perbedaan-perbedaan yang sangat penting dalam spesifikasi objeknya, tehnik-tehnik pengukurannya, dan metode analisisnya.

\section{E. Undang-undang RI no.20 tahun 2003 tentang Sistem Pendidikan Nasional}

Undang-Undang RI no. 20 tahun 2003 tentang Sistem Pendidikan Nasional, dibuat karena adanya tuntutan diterapkannya prinsip demokrasi, desentralisasi, keadilan dan menjunjung tinggi hak asasi manusia dalam kehidupan berbangsa dan bernegara. Dalam hubungannya dengan pendidikan, prinsip-prinsip tersebut akan memberikan dampak yang mendasar pada kandungan, proses dan manajemen sistem pendidikan.

\section{METODOLOGI}

Format desain penelitian evaluasi penerapan Undang-undang no. 20 tahun 2003 tentang Sisdiknas dalam penyelenggaraan pendidikan tenaga kesehatan program D-III Keperawatan menggunakan desain Kualitatif. Metode yang digunakan ini untuk menganalisis kebijakan penyelenggaraan pendidikan D-III Keperawatan menggunakan metode NVIVO versi 8, merupakan sebuah program komputer untuk membantu dalam analisis data kualitatif.

\section{HASIL PENELITIAN}

\section{a. Hasil Kinerja Implementasi Kebijakan}

Berdasarkan hasil identifikasi data dari ke-6 komponen yang saling berkaitan tersebut diatas, maka dapat diperoleh gambaran bahwa implementasi kebijakan penyelenggaraan pendidikan nasional pada penyelenggaraan pendidikan D-III Keperawatan hasilnya dasarnya tidak terimplementasi dengan baik, karena ada pihak-pihak yang terlibat dalam pelaksanaan ini tidak dapat bekerja sama secara efektif dan efisien, disamping karena adanya pihak yang tidak memahami permasalahan sepenuhnya.

Memperhatikan waktu diterbitkannya UU no. 20 tahun 2003 sampai tahun 2011 ( \pm selama 7 tahun) dan hasil dari implementasi kebijakan yang dirasakan, maka dapat diprediksi bahwa Implementasi kebijakan UU no. 20 tahun 2003, memiliki resiko gagal disebabkan karena pelaksanaannya yang jelek (bad execution). Untuk memperoleh gambaran dari pelaksanaan kebijak Sistem Pendidikan Nasional dapat terlihat dari survey sebagai berikut:

a) Status kepemilikan Institusi D-III Keperawatan

Diperoleh data dari D-III Keperawatan di provinsi DKI Jakarta, ternyata 33 institusi $(86.8 \%)$ dimiliki oleh swasta/masyarakat, sedangkan 4 institusi (10.5\%) dimiliki oleh ABRI dan 1 institusi (2.6\%) milik pemda.

b) Pembinaan Institusi

Diperoleh data bahwa institusi pendidikan D-III Keperawatan di DKI Jakarta mendapatkan pembinaan paling banyak dari Depkes melalui Pusdiknakes sebanyak 16 institusi (42.1\%), kemudian 15 institusi memperoleh pembinaan melalui kedua-dua departemen (39.5\%) dan yang paling sedikit adalah institusi yang benar-benar murni mengikuti pembinaan dari Diknas melalui kopertis hanya 7 institusi (18.4\%). Hal tersebut terlihat dari table dibawah ini : 
c) Institusi telah menjalankan UU No. 20 tahun 2003

Diperoleh data bahwa institusi pendidikan di DKI Jakarta yang telah menjalankan peraturan perundang-undangan dibidang pendidikan menunjukkan bahwa hanya 2 institusi (5.3\%) yang telah mengikuti UU Sisdiknas sedangkan 36 institusi (94.7\%) belum mengikuti UU Sisdiknas tersebut.

d) Tri Dharma Pendidikan program D-III Keperawatan

1) Dharma ke-1: Pendidikan program D-III Keperawatan

Pelaksanaan dharma ke-1 dari tridharma perguruan tinggi, $100 \%$ seluruh institusi telah menjalankan fungsi pendidikan pengajaran. Hal tersebut memperlihatkan bahwa institusi pendidikan telah menjalankan fungsi pertamanya dengan baik.

2) Dharma ke-2: Penelitian program D-III Keperawatan

Penyelenggaraan Dharma penelitian yang dilakukan oleh institusi D-III Keperawatan di DKI Jakarta. Penyelenggaraan Dharma penelitian yang dilakukan oleh institusi D-III Keperawatan di DKI Jakarta. Pada fungsi ke-2 ini, mulai memperlihatkan kondisi yang paradok dibidang pendidikan. Seharusnya penelitian dilakukan oleh para dosen, tetapi fakta dilapangan sebanyak 89,5\% tidak pernah melaksanakan penelitian, selebihnya $10,5 \%$ saja yang melaksanakan penelitian, Tentunya kondisi tersebut mencerminkan institusi pendidikan yang sangat ironis.

3) Dharma ke-3: Pengabdian Masyarakat program D-III Keperawatan

Penyelenggaraan Tridharma ke-3 pengabdian masyarakat dapat dilaksanakan pada semua institusi yaitu $100 \%$. Kondisi tersebut berkaitan dengan dengan beberapa factor diataranya adalah target kegiatan mahasiswa keperawatan yang berkaitan dengan Mata Ajar Komunitas adalah pembinaan Daerah Binaan, sehingga peluang untuk melakukan pengabdian masyarakat menjadi otomatis. Tetapi bila ditinjau dari berapa banyak pengabdian masyarakat yang dilakukan hasilnya menjadi berbeda yaitu sering dilakukan sebanyak $89,5 \%$ dan kadangkadang sebanyak $4 \%$

e) Dosen Memiliki jenjang Kepangkatan pada program D-III Keperawatan

Sebagian besar dosen di Akademi Keperawatan di DKI belum ,memiliki jenjang kepangkatan sebanyak 89,5\% sedangkan yang telah memilki jenjang keangkatan baru $10,5 \%$ saja.

f) Sumber Dana Institusi program D-III Keperawatan

Sumber dana yang diperoleh institusi untuk menjalankan operasional dari institusi pendidikannya 92,1\% berasal dari masyarakat, dalam hal ini dari SPP yang dibayarkan oleh mahasiswa. Sedangkan pasang sedikit berasal dari pemerintah daerah $2,6 \%$

g) Evaluasi Pengendalian Mutu program D-III Keperawatan

Pelaksanaan evaluasi pengendalian mutu dari institusi program D-III Keperawatan 97,4\% dilakukan oleh institusi sendiri .

h) Akreditasi Institusi program D-III Keperawatan

Akreditasi dilaksanakan institusi program D-III Keperawatan dilakukan oleh Pusdiknakes dan Dinas KEsehatan sebanyak 86,8 \% sedangkan institusi yang di akreditasi oleh BAN-PT hanya 13,5\%

i) Penerbitan Ijazah mahasiswa program D-III Keperawatan 
Ijazah yang diterima oleh mahasiswa Institusi Program D-III Keperawatan diterbitkan oleh Pusdiknakes yaitu sebayak 33 institusi $(86,8 \%)$ sedangkan ijazah yang diterbitkan oleh institusi hanya 5 institusi $(13,2 \%)$

Sedangkan hasil implementasi yang dirasakan yang dirasakan informan melalui pelaksanaan FGD dan wawancara mendalam terlihat terlihat dari pemaknaan sebagai berikut:

1) Manfaat Alih Bina

Manfaat yang dirasakan oleh penyelenggara pendidikan D-III Keperawatan dalam melaksanakan alih bina adalah: penyelenggara pendidikan D-III keperawatan memahami untuk beralih bina tetapi sulit untuk merealisasikannya.

\section{PENUTUP}

\section{Kesimpulan}

1. Kebijakan penyelenggaraan pendidikan menurut UU no. 20 tahun 2003 tentang Sistem Pendidikan Nasional pada dasarnya momentum Reformasi dalam penyelenggaraan pendidikan D-III keperawatan menuju peningkatan mutu yang lebih baik. Tindakan operasional yang dilakukan adalah melakukan "Alih Bina" . Peralih pembinaan ternyata belum sepenuhnya dapat dilakukan oleh semua institusi penyelenggara pendidikan D-III Keperawatan masih adanya resistensi dari regulator penyelenggara pendidikan D-III keperawatan Dinas Kesehatan

2. Penyelenggara pendidikan D-III Keperawatan pada prinsipnya telah memahami UU no. 20 tahun 2003 tetapi tidak memiliki keberanian untuk melakukan alih bina secara konsisten mengingat banyak kondisi dilematis yang akan dihadapi oleh penyelenggara pendidikan bila melakukan alih bina. Dilematis yang dihadapi adanya ancaman tidak diterimanya lulusan dari penyelenggara pendidikan D-III Keperawatan di Rumah Sakit, tempat lapangan pekerjaan lulusan dari akademi Keperawatan. Sehingga muncul dualisme ljazah dari penyelenggara pendidikan DIII Keperawatan yaitu ijazah yang diterbitkan oleh pihak Depkes dan ijazah yang diterbitkan oleh institusi

3. Hasil implementasi Undang-undang no 20 tahun 2003 pada penyelenggaraan pendidikan tenaga kesehatan program D-III Keperawatan pada dasarnya tidak terimplementasi dengan baik, karena pihak-pihak yang terlibat dalam pelaksanaan ini kebijakan tidak dapat bekerja sama secara efektif dan efisien. Memperhatikan waktu dan hasil dari implementasi kebijakan dapat diprediksi bahwa ada kecenderungan Implementasi kebijakan UU no. 20 tahun 2003, memiliki resiko gagal disebabkan karena pelaksanaannya yang jelek (bad execution).

4. Langkah strategis untuk menghindari terjadinya kegagalan maka pemerintah dalam hal ini Departemen Pendidikan Nasional sebagai penanggung jawab pendidikan di Indonesia dapat mengimplementasikan kebijakan secara tegas dan tidak melakukan tindakan-tindakan eksperimen untuk mengatasi konflik yang berkepanjangan. Sedangkan Depkes yang memiliki sejarah mengatur penyelenggaraan pendidikan D-III dapat menyelesaikan manajemen transisi dengan tuntas, sehingga tidak ada lagi resistensi dari pihak Dinas Kesehatan.

5. Kendala dari penerapan Undang-Undang no. 20 tahun 2003 pada Program D-III Keperawatan adalah Resistensi dari pemerintah daerah, sehingga secara psikologis mempengaruhi penyelenggara pendidikan untuk mengimplementasi kebijakan UU no.20 tahun 2003. 
6. Kekuatan dari penerapan Undang-Undang no. 20 tahun 2003 adalah kejelasan penyelenggaraan pendidikan dan diberikannya otonomi institusi untuk mengatur akademik, dan operasional pendidikan secara bertanggung jawab. Kelemahan adalah ketidakjelasan sikap yang harus diambil oleh institusi, ketidak ketegasan sikap dari pemerintah dalam hal ini Kemendiknas dan Kemenkes, masih adanya ambiguitas dalam penerapan Undang-Undang tersebut. Hambatan adalah masih adanya Resisensi dari pelaksana kebijakan ditingkat daerah dalam hal ini Dinas Kesehatan serta belum dipahaminya Undang-Undang tersebut oleh pengelola pendidikan. Peluang adalah munculnya Peraturan Pemerintah no. 17 tahun 2010, sebagai peluang untuk mengatasi kelemahan dan keraguan dari institusi untuk beralih bina atau untuk dilakukannya alih bina. Tantangan adanya tuntutan masyarakat terhadap kualitas tenaga keperawatan di RS serta tuntutan masyarakat terhadap mutu pendidikan tinggi.

Bentuk ideal dari penyelenggaraan pendidikan D-III keperawatan adalah pendidikan tinggi yang diatur oleh 1 Departemen dalam hal ini Kemendiknas) dan mutu dari profesi keperawatan dapat diatur oleh pihak Depkes, dengan mengadakan uji kompetensi bagi lulusan dari institusi pendidikan, sehingga lulusan laik ditempatkan di RS yang dibina oleh Depkes.

\section{Saran}

1. Pihak Depkes dalam hal ini Pusdiknakes dan Dinas Kesehatan dapat mensosialisasikan secara jelas mengenai penerapan UU no. 20 tahun 2003 tanpa harus adanya ancaman-ancaman sehingga institusi pendidikan dapat membuat keputusan "alih bina" secara konsisten

2. Peraturan pemerintah no 17 tahun 2010 dapat dijalankan, untuk mengurangi berbagai keraguan yang dirasakan oleh Departemen Kesehatan cq Pusdiknakes cq Dinas Kesehatan implementasi kebijakan penyelenggaraan pendidikan program DIII Keperawatan

3. Sosialisasi bahkan pemberian surat edaran resmi kepada Rumah sakit mengenai status penyelenggaraan pendidikan D-III Keperawatan dan penjelasan legalitas ijazah yang diterbitkan oleh masing-masing institusi penyelenggara pendidikan DIII Keperawatan

4. Dibuka secara luas program pendidikan S-2 Keperawatan untuk meningkatkan kualifikasi tenaga pendidik yang sesuai dengan peraturan perundang-undangan yang ada sehingga jenjang akademik bagi dosen-dosen dapat terealisasi

5. Penelitian lebih lanjut mengenai Resistensi dari Pemerintah daerah dalam melakukan alih bina Undang-Undang RI no. 20 tahun 2003.

6. Hubungan yang jelas antar departemen yang terkait dengan pendidikan Keperawatan-Rumah Sakit diikat dalam suatu hubungan trilateral pada tingkat regional, nasional dan multinasional, sehingga Pemerintah dapat mendorong institusi untuk menjadi elemen kunci dalam pelaksanaan kebijakan untuk melakukan perubahan.

7. Segera dilaksanakan Uji kompetensi bagi seluruh lulusan dari Akademi Keperawatan yang akan bekerja di Rumah sakit.

8. Perlu dibentuk suatu dewan (board) atau majelis (council) pendldlkan keperawatan yang berfungsi menentukan kebijakan serta memantau penyelenggaraan pendidikan keperawatan. 
9. Pengesahan Undang-Undang Keperawatan untuk memperjelas tata aturan dari profesi Keperawatan dalam menjalankan profesionalisnenya

\section{DAFTAR PUSTAKA}

Dunn, William (1999). Analisa Kebijakan Publik. Yogyakarta: Gadjah Mada Press.

Dunn, William N, (2007). Publik policy analysis : a introduction-4th ed. Person. Prentie Hall. New Jersey

Jones ,Charles O (1996). Pengantar Kebijakan Publik, Manajemen PT Raja Grafindo Persada, Cetakan ke-3,. Jakarta.

Langbein, Laura Irwin (1980). Discovering Whiter Program Work: Guide to Statictical Method for Program Evaluation, Scott, Foresman and Company Glenview. Illinois. United Stated of America

Matland, Richard E.(1995). Syntesizing the Implemntation Literature : The Ambiguity-Conflik Model of policy Implementation, Journal of Publik Administration Research and Theory PART,Vol.5,No.2 (April 1995), Oxford University Press and Publik Management Research Assosiation.

Robert Eyestone (1971). The Threads of Policy: A study in Policy Leadership. Indianapolis: Bobbs-Merril,hlm.18.

Rossi, Peter. S, at all (1979). Evaluation: A systematic Approach, Sage Publikation, Beverly Hill, London.

Thomas R.Dye (1975) Understanding Publik Policy. Second Edition. Engelwood Cliff, N.J: Prentice-Hall,hlm.1.

Weiss, Carol H (1972)., Evaluastion Research: Method for Assessing Program Effectiveness, Prentice Hall, Inc., Englewood Clift, New Jersey 
